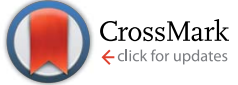

Cite this: RSC Adv., 2016, 6, 26380
Received 18th January 2016 Accepted 29th February 2016

DOI: 10.1039/c6ra01511e

www.rsc.org/advances

\section{Carbide-derived carbon in polypyrrole changing the elastic modulus with a huge impact on actuation}

\author{
Z. Zondaka, R. Valner, T. Tamm, A. Aabloo and R. Kiefer*
}

While carbide-derived carbon (CDC)-based materials have shown stable behavior in ionic electro-chemomechanical actuators, the displacement and actuation speed have remained low compared to conducting polymer-based actuators. The goal of this research was to obtain more responsive conducting polymerCDC composite films and to investigate their linear actuation properties, comparing the stress and strain to those of polypyrrole (PPy) doped with dodecylbenzenesulfonate (DBS ${ }^{-}$). The PPy-CDC hybrid films were synthesized electrochemically using polyoxometalate (POM) (phosphotungstic acid) to attach charge to the CDC particles for embedding them into the PPy matrix as secondary dopants in addition to $\mathrm{DBS}^{-}$. Cyclic voltammetry and square wave potential steps in electro-chemo-mechanical deformation (ECMD) measurements were performed in aqueous electrolyte solution, showing that the PPy-CDC hybrids had higher strain $(12 \%)$ and stress $(0.6 \mathrm{MPa})$ than the PPy/DBS films. The new composite was investigated by scanning electron microscopy (SEM) and energy dispersive X-ray (EDX) spectroscopy to evaluate the composition of these promising materials.

\section{Introduction}

Linear conducting polymer actuators have been widely studied in the last decades ${ }^{\mathbf{1 - 3}}$ with the main focus being on strain and stress optimization. PPy/TFSI and $\mathrm{PPy} / \mathrm{CF}_{3} \mathrm{SO}_{3}$ linear actuators have shown strain in the order of $20-30 \%{ }^{4}$ The most common conducting polymer actuators have been based on PPy doped with $\mathrm{DBS}^{-}$(PPy/DBS). The bulky $\mathrm{DBS}^{-}$ions typically behave as macroanions $\left(\mathrm{MA}^{-}\right)$immobilized during electropolymerization, leading to mainly cation-driven actuation ${ }^{5}$ with strain in the range of $2 \%$ and a maximal stress of $0.5 \mathrm{MPa} .^{6}$ The driving electrochemical reaction can be summarized as reaction (1): ${ }^{7}$

$$
\begin{aligned}
{\left[\left(\mathrm{PPy}^{0}\right)\left(\mathrm{MA}^{-}\right)_{n}\left(\mathrm{C}^{+}\right)_{n}(\mathrm{~S})_{m}\right]_{\mathrm{gel}} \leftrightarrows } & {\left[\left(\mathrm{PPy}^{n+}\right)\left(\mathrm{MA}^{-}\right)_{n}\right]_{\mathrm{s}} } \\
& +n\left(\mathrm{C}^{+}\right)_{\mathrm{aq}}+n \mathrm{e}^{-}+m \mathrm{~S}
\end{aligned}
$$

Reaction (1) shows the simplest model for cation $\left(\mathrm{C}^{+}\right)$and water (solvent, $\mathrm{S}$ ) ingress in PPy-DBS compensating for the negative charge of the immobile macroanion $\left(\mathrm{MA}^{-}\right.$, here $\mathrm{DBS}^{-}$) in reduced PPy films (left side). Upon oxidation (right side of reaction (1)) the electro-generated positive charges of $\mathrm{PPy}^{n+}$ are compensated for by the trapped macroanions forming solids (s). As a consequence, the PPy/DBS film expands on reduction and shrinks on oxidation. ${ }^{8}$ An inherent shortcoming of conducting polymers is the low conductivity in the reduced state, affecting the rate of response of actuators. Carbon materials

Intelligent Materials and Systems Lab, Institute of Technology, University of Tartu, Nooruse 1, 50411 Tartu, Estonia.E-mail: rudolf.kiefer@ut.ee such as CDC, ${ }^{9}$ nanotubes ${ }^{\mathbf{1 0}}$ or carbon black ${ }^{\mathbf{1 1}}$ have been included in PPy/DBS films during electropolymerization for increased conductivity while also increasing capacitance. ${ }^{\mathbf{1 2}}$ Another option is the electropolymerization of PPy on carbon-based materials serving as the conductive electrode, resulting in composite materials with enhanced actuation properties. ${ }^{\mathbf{9}, \mathbf{1 3}}$ Recent research ${ }^{9}$ did reveal that successful coupling of CDC and PPy resulted in hybrids with diametrical strain in the range of $13 \%$, close to that of PPy/DBS. The main charging/discharging mechanism of conducting polymers follows the oxidation/ reduction process (faradaic) ${ }^{\mathbf{1 4 , 1 5}}$ while for CDC materials (nonfaradaic) an electrical double layer (EDL) charging process dominates. ${ }^{16}$ Therefore, mixed charging/discharging processes can occur in the hybrid material. Our goal in this research was to investigate the novel PPy-CDC hybrid films and their linear actuation properties of strain and stress. To solubilize carbon particles in aqueous solution, charge needs to be added. In recent research, ${ }^{17} \mathrm{CNTs}$ have been solubilized with an inorganic agent based on polyoxometalates (phosphotungstic acid). Polyoxometalates consist of a specific metal-oxygen structure with the general formula $\left[\mathrm{M}_{x} \mathrm{O}_{y}\right]_{n}{ }^{-}(\mathrm{M}=\mathrm{V}, \mathrm{Mo}, \mathrm{W}),{ }^{18}$ and in most cases the Keggin-type POM $\left[\mathrm{PW}_{12} \mathrm{O}_{40}\right]^{3-}$ has been applied in combination with $\mathrm{PPy},{ }^{\mathbf{1 9} 20}$ resulting in films with high capacitance. Incorporating metal nanoparticles over a POM carrier into PPy also has led to improved conductivity. ${ }^{21}$ The actuation properties of free-standing PPy-CDC/POM-DBS (PPy-CDC) films have not been investigated so far and in this work we compare their properties with PPy/DBS films in the form of isotonic (constant length) and isometric (constant force) ECMD 
measurements. The electrochemical measurements (cyclic voltammetry and chronopotentiometry) were performed in socalled steady state conditions (charging/discharging in balance $^{7}$ ) following the ESCR model, to ensure that no irreversible (over-oxidation or over-reduction) processes take place during the redox cycles. ${ }^{22,23}$ SEM imaging of the films (PPy-CDC and PPy/DBS) was applied to investigate the difference in morphology. EDX measurements were used to study the stability and mechanism of charge compensation during actuation cycles.

\section{Materials and methods}

\section{Materials}

Amorphous titanium carbide-derived carbon (TiC-800) was purchased from Skeleton Technologies Ltd. Solvent ethylene glycol (EG, 99.8\%) was from Fluka. Pyrrole (Py, $\geq 98 \%$, SigmaAldrich) was vacuum-distilled prior to use and stored at low temperature in the dark. Polyoxometalate (POM) in the form of phosphotungstic acid $\left(\mathrm{PW}_{12} \mathrm{O}_{40}{ }^{3-}\right)$ hydrate was from SigmaAldrich. Lithium bis(trifluoromethanesulfonyl)imide (LiTFSI, 99.95\%) was purchased from Solvionic. Sodium dodecylbenzenesulfonate (technical grade) was acquired from Aldrich. Milli$\mathrm{Q}+$ water was used for solutions.

\section{Electrochemical polymerization}

Electrochemical synthesis of electroactive PPy/DBS and PPyCDC films was carried out in a two-electrode electrochemical cell. The bath for the PPy/DBS films contained 0.1 M NaDBS in EG : Mili-Q+ solution with a ratio of $1: 1$ and $0.1 \mathrm{M}$ pyrrole. PPy-CDC films were made in the same way with the addition of 1\% CDC and $0.1 \mathrm{M}$ phosphotungstic acid. Both solutions were sonicated for $30 \mathrm{~min}$ in an ice bath and stored in a fridge prior to electrochemical polymerization. Galvanostatic polymerization was carried out at $0.1 \mathrm{~mA} \mathrm{~cm}^{-2}$ for $40000 \mathrm{~s}$ at $-20{ }^{\circ} \mathrm{C}$, using a stainless steel sheet as the working electrode and a stainless steel mesh as the counter electrode. After polymerization, the films were extracted from the stainless steel, washed in ethanol to remove residues of pyrrole and then in water to remove excess NaDBS. The films were stored in 0.1 M NaDBS aqueous solution. The film thickness of PPy/ DBS was in the range of $20 \mu \mathrm{m}$ and that of PPy-CDC was in the range of $26 \mu \mathrm{m}$.

\section{Electro-chemo-mechanical measurements}

For ECMD measurements, the PPy/DBS and PPy-CDC films were cut into $20 \times 1 \mathrm{~mm}$ strips and immersed in $0.2 \mathrm{M} \mathrm{LiTFSi}$ aqueous solution. The films were fixed on the gold contact/ electrode of a force sensor (TRI202PAD, Panlab) at the fixed arm on the linear muscle analyzer setup (Fig. 1).

A platinum sheet was used as the counter electrode with $\mathrm{Ag} / \mathrm{AgCl}(3 \mathrm{M} \mathrm{KCl})$ as the reference electrode. The in-house ECMD measurement setup had a movable force sensor giving an advantage over commercially available systems, where the force sensors are static. Our setup allows determination of factor $k\left(\mathrm{mg} \mu \mathrm{m}^{-1}\right)$, which is the mass $(\mathrm{mg})$ required to cause

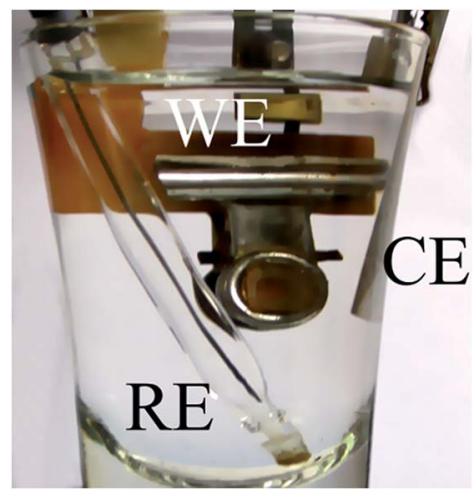

Fig. 1 Image of the measurement cell with the electrolyte in a threeelectrode setup with a reference electrode (RE), counter electrode (CE) and the PPy-CDC film connected as the working electrode (WE).

a $1 \mu \mathrm{m}$ length change of a film. For the films used in our

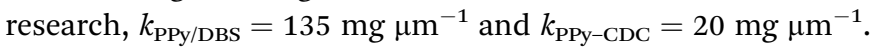
The force (isotonic, constant length), and the length change (isometric, constant force of $11.5 \mathrm{mN}$ ) were measured in real time while running cyclic voltammetry (CV) with a scan rate of $5 \mathrm{mV} \mathrm{s}^{-1}$, within the voltage range of $0.25 \mathrm{~V}$ to $-0.8 \mathrm{~V}$, and with the square wave potential at frequencies $0.0025 \mathrm{~Hz}, 0.005 \mathrm{~Hz}$, $0.01 \mathrm{~Hz}, 0.025 \mathrm{~Hz}, 0.05 \mathrm{~Hz}$ and $0.1 \mathrm{~Hz}$.

\section{Characterization of polymerized films}

Both PPy/DBS and PPy-CDC films were characterized using scanning electron microscopy (Helios NanoLab 600, FEI) and energy dispersive X-ray spectroscopy (Oxford Instruments with $\mathrm{X}$-Max $50 \mathrm{~mm}^{2}$ detector). Before characterization, $5 \mathrm{~min}$ polarization at $-1.0 \mathrm{~V}$ and $+1.0 \mathrm{~V}$ was performed for reduced and oxidized films, respectively. The surface and cross-section area of the fresh, not actuated, oxidized and reduced films was also examined with SEM and EDX spectroscopy.

\section{Results and discussion}

\section{Polymerization and morphology}

PPy/DBS and PPy-CDC were deposited on a stainless steel electrode and could be easily removed as free-standing films. Typical polymerization curves of the PPy/DBS and PPy-CDC films are shown in Fig. 2.

During the polymerization process of the PPy/DBS and PPyCDC films, the voltage reached $2.2 \mathrm{~V}$ and $1.5 \mathrm{~V}$, respectively. It has been shown before ${ }^{24}$ that potentials up to $1.2 \mathrm{~V}$ are required to assure the deposition of PPy in the presence of POM. We expect that POM-CDC, due to its electrocatalytic properties, ${ }^{20}$ reduces the formation potential of the conducting polymer. The corresponding SEM images of PPy/DBS and PPy-CDC are shown in Fig. 3.

The SEM image of PPy/DBS in Fig. 3a (surface, cross-section in the inset) shows a smooth and compact structure with the typical PPy cauliflower morphology. ${ }^{25}$ In Fig. 3b, larger particles of PPy-CDC can be identified as CDC is surrounded by PPy with a similar rough morphology as seen elsewhere. ${ }^{9}$ 


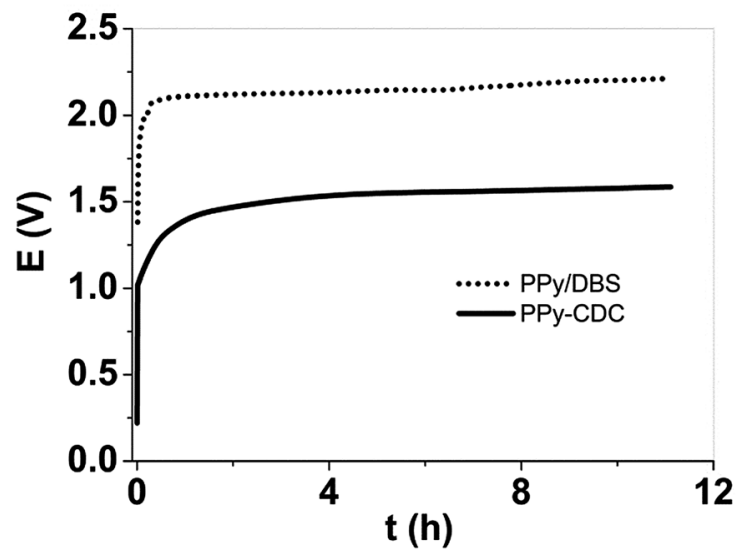

Fig. 2 Polymerization curves of PPy/DBS (dotted line) and PPy-CDC (solid line). Polymerization was performed at $1.8 \mathrm{~mA}$ (surface area of $18 \mathrm{~cm}^{-2}$ ) and at $-20^{\circ} \mathrm{C}$ in a solution consisting of ethylene glycol and water in a $1: 1$ ratio.
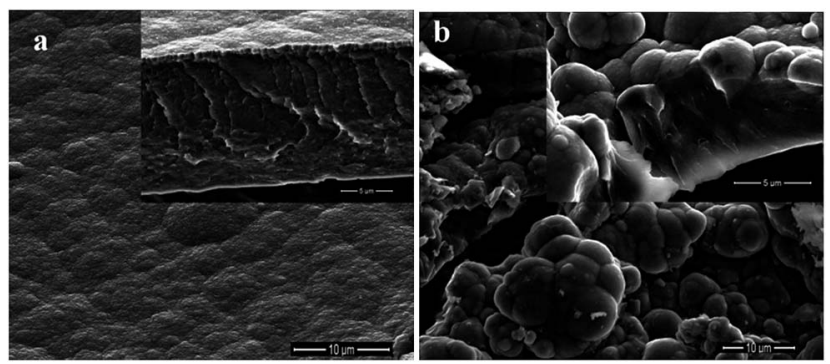

Fig. 3 Scanning electron microscopy images of (a) PPy/DBS and (b) PPy-CDC surface and cross-section of the films (polarized at $1 \mathrm{~V}$ for 5 minutes).

\section{Cyclic voltammetry ECMD measurements}

CV ECMD measurements of the PPy/DBS and PPy-CDC films were made in LiTFSI aqueous electrolyte solution. For both films the potential range was chosen from $0.25 \mathrm{~V}$ to $-0.8 \mathrm{~V}$ in a three-electrode system (counter electrode: platinum sheet, reference electrode: $\mathrm{Ag} / \mathrm{AgCl}(3 \mathrm{M} \mathrm{KCl}))$. Cyclic voltammetry (strain, stress $v s$. time and current density $v s$. potential) results are shown in Fig. 4.

PPy/DBS linear actuators showed strain in the range of $0.6 \%$ (Fig. 4b) and stress of $0.425 \mathrm{MPa}$. The strain of the PPy-CDC linear actuators reached $13 \%$ and the stress reached $0.64 \mathrm{MPa}$ (Fig. 4a and b). The CV shape for PPy/DBS (Fig. 4c) reveals an oxidation peak at $-0.08 \mathrm{~V}$ and the reduction wave was found at $-0.53 \mathrm{~V}$. The benefit of the increased conductivity and capacity of the carbon material of PPy-CDC is indicated by the more capacitor-like shape of the $j v s$. $E$ curve, in agreement with the mixed mechanisms ${ }^{9}$ of the EDL with a capacitance from CDC and the redox (faradaic) processes of PPy. The nearly 20 times higher strain of PPy-CDC in comparison to that of PPy/DBS is attributed to the physical properties of the films. Adding CDC material in PPy/DBS films leads to a lower film rigidity, ${ }^{9}$ and the other important reason for the lower elastic modulus (7 MPa for
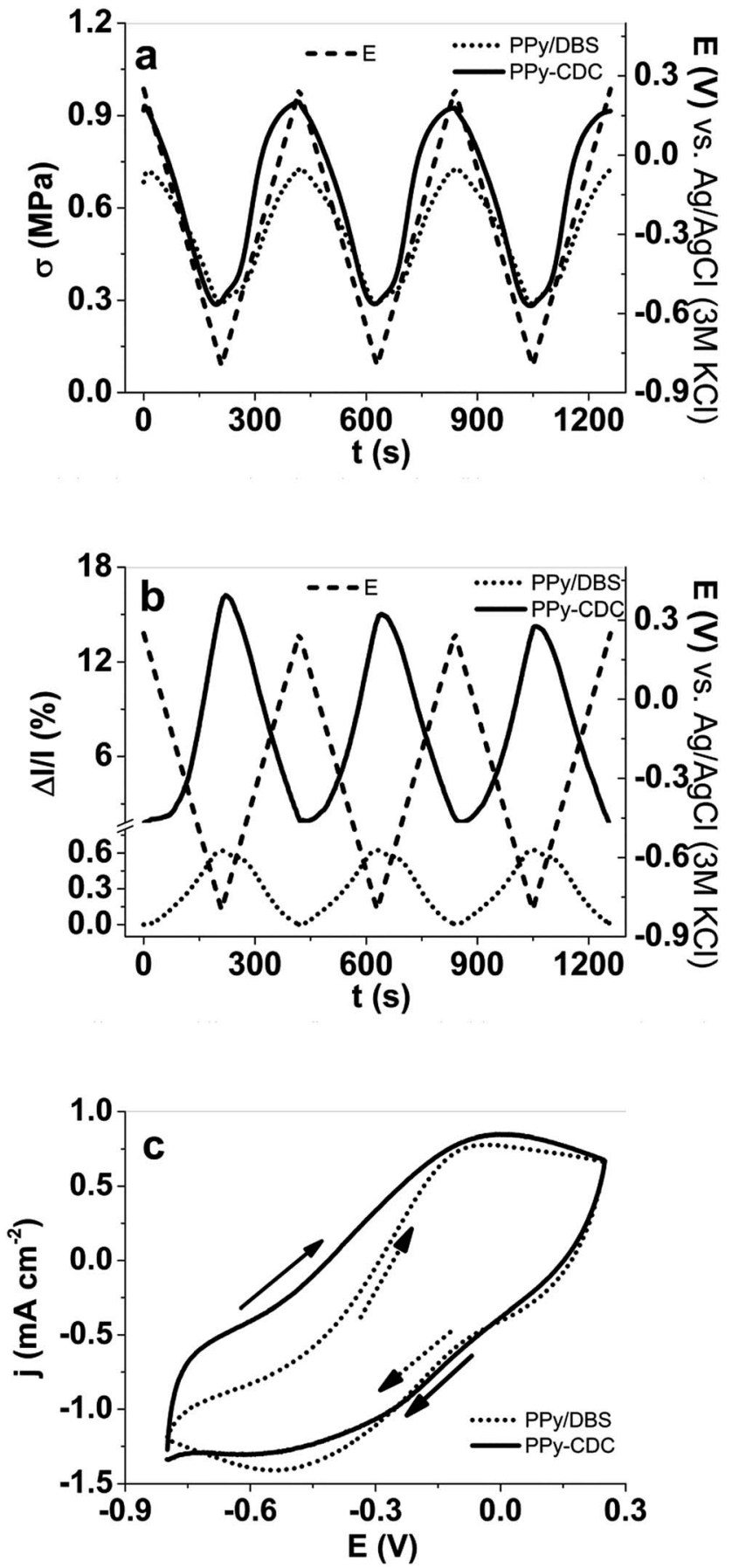

Fig. 4 ECMD CV $\left(5 \mathrm{mV} \mathrm{s}^{-1}, 0.25 \mathrm{~V}\right.$ to $-0.8 \mathrm{~V}$, vs. $\mathrm{Ag} / \mathrm{AgCl}(3 \mathrm{M} \mathrm{KCl})$ reference) of PPy/DBS (dotted line) and PPy-CDC (solid line): (a) stress $(\sigma)$ vs. time ( 3 cycles) with potential $E$ (dashed line); (b) strain vs. time (3 cycles) with potential $E$ (dashed line) (the strain for PPy-CDC starts at $2 \%$ as the lowest point); (c) current density $j$ vs. applied potential $E$. The arrows indicate the start and end points of the $3^{\text {rd }}$ cycle.

PPy-CDC vs. $70 \mathrm{MPa}$ for PPy/DBS) could be the lowered synthesis potential, resulting in fewer cross-links and other chain defects. To investigate the charge density of the two different linear films at frequencies from $0.0025 \mathrm{~Hz}$ to $0.1 \mathrm{~Hz}$, square wave ECMD measurements were performed. 

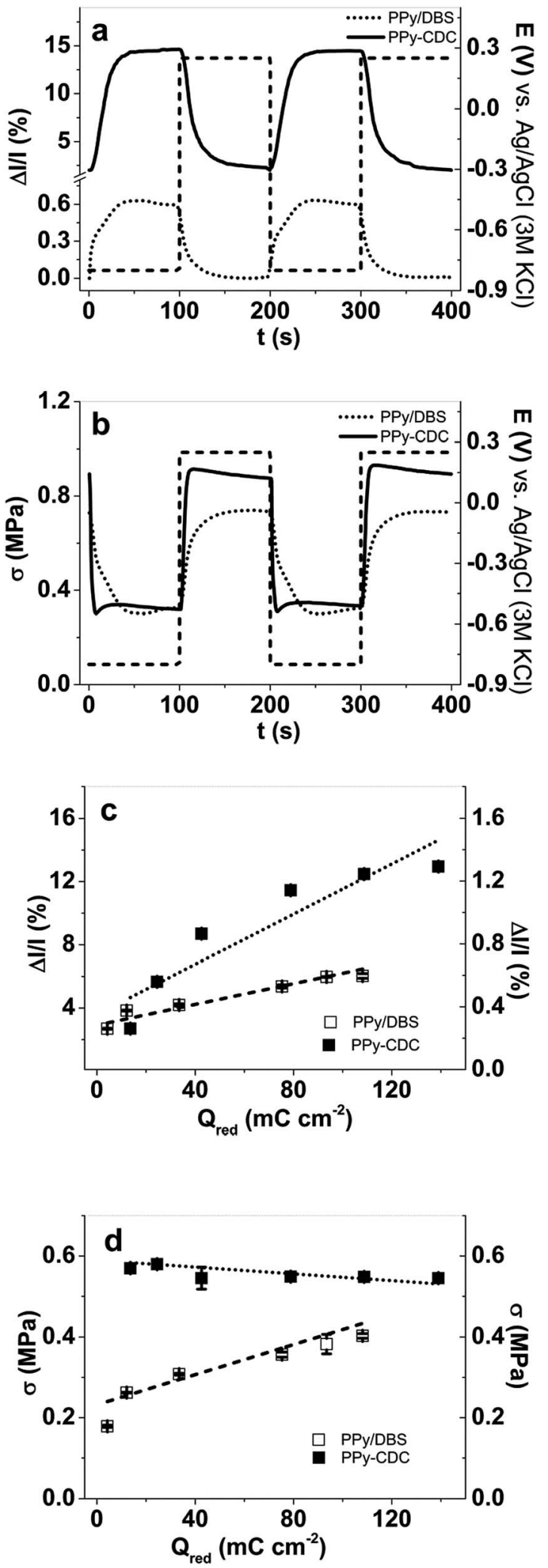

Fig. 5 ECMD square wave potential measurements $(0.25-0.8 \mathrm{~V})$ for PPy/DBS (dotted line) and PPy-CDC (solid line) of (a) 2 cycles of strain curves at $0.0025 \mathrm{~Hz}$ frequency with applied potential $E$ (dashed line) vs. time $t$ (strain for PPy-CDC is presented here at the lowest point at $2 \%$ ), and (b) 2 cycles of stress curves at $0.005 \mathrm{~Hz}$ frequency with applied potential $E$ (dashed line) vs. time $t$. (c) Strain values (mean values with standard regression) at frequencies from $0.0025 \mathrm{~Hz}$ to $0.1 \mathrm{~Hz}$ vs.

\section{Square wave potential (SWP) ECMD measurements}

Isotonic and isometric ECMD SWP (square wave potential) measurements of PPy/DBS and PPy-CDC were made in LiTFSI aqueous electrolyte solution. For both films the potential range from $0.25 \mathrm{~V}$ to $-0.8 \mathrm{~V}$ was applied. The results are presented in Fig. 5 .

Isotonic ECMD square wave potential measurements (2 cycles, $0.005 \mathrm{~Hz}$, Fig. 5a) reveal for PPy/DBS strain in the range of $0.5 \%$ and stress (Fig. $5 \mathrm{~b}$ ) of $0.4 \mathrm{MPa}$. PPy-CDC showed strain in the range of $12 \%$ and stress around $0.57 \mathrm{MPa}$. Importantly, PPy-CDC not only had higher stress and strain but the response of both stress and strain to voltage steps was also significantly faster and saturated quickly. It needs to be pointed out that the actuation is cation-driven (expansion upon reduction) and the solvated $\mathrm{Li}^{+}$cations balance the negative charge of the immobilized DBS $^{-}$ions in PPy/DBS as well as the additional negatively charged CDC-POM complexes in PPy-CDC. In the case of PPy-CDC, a larger variety and more bulky macroanions (DBS ${ }^{-}$, $\mathrm{POM}^{-}$and $\mathrm{CDC}-\mathrm{POM}^{-}$) are entrapped in the film. The plots of strain and stress $v s$. charge density are shown in Fig. $5 \mathrm{c}$ and d, respectively. As expected, in PPy/DBS linear actuators the strain and stress rise with increased charge density. ${ }^{26}$ In the case of PPy-CDC, the strain was also dominated by PPy expansion and contraction and had similar behavior, while the EDL charging process of CDC reduced the impact of charge with only a slight decrease of stress from 0.58 to $0.54 \mathrm{MPa}$, (Fig. 5d, black squares). To investigate the durability of the PPy/DBS and PPyCDC linear actuators, consecutive square wave potential steps (100 cycles at $0.1 \mathrm{~Hz}$ ) were recorded and are presented in Fig. 6a and $\mathrm{b}$.

At $0.1 \mathrm{~Hz}$, the PPy/DBS linear actuators showed nearly constant strain in the range of $0.26 \pm 0.002 \%$ with a charge density of $4.2 \pm 0.2 \mathrm{mC} \mathrm{cm}^{-2}$ (Fig. 6a). The PPy-CDC strain for 100 cycles of square wave potential steps between $0.25 \mathrm{~V}$ and $-0.8 \mathrm{~V}$ showed strain an order of magnitude higher of $2.9 \pm$ $0.13 \%$ at 2.5 times higher charge density of $10.7 \pm 1 \mathrm{mC} \mathrm{cm}^{-2}$. The complexes of CDC-POM in the PPy film contribute to increased charging/discharging but also lower the modulus of the film, having an impact on the strain values (Fig. 6b). The stability of both the strain and exchanged charge density was also comparable to that of PPy/DBS actuators.

\section{EDX spectra}

The presence of tungsten from POM inside the PPy-CDC films even after actuation was verified by EDX spectroscopy (Fig. 7).

The actuated (1000 square wave cycles) samples were first reduced at $-1 \mathrm{~V}$, and cut in half with one half then oxidized at $1 \mathrm{~V}$ in the aqueous electrolyte. The high reduction and oxidation potentials of $\pm 1 \mathrm{~V}$ were chosen to obtain fully charged and discharged films. The presence of tungsten $(1.77 \mathrm{keV})$ in all the PPy-CDC films (Fig. 7b) is clearly observed, however, the W : C

charge density $Q$ (high charge density at frequency $0.0025 \mathrm{~Hz}$ and low charge density at $0.1 \mathrm{~Hz}$ ) and (d) stress values $(\sigma)$ at frequencies from $0.0025 \mathrm{~Hz}$ to $0.1 \mathrm{~Hz}$ vs. charge density $Q$. 

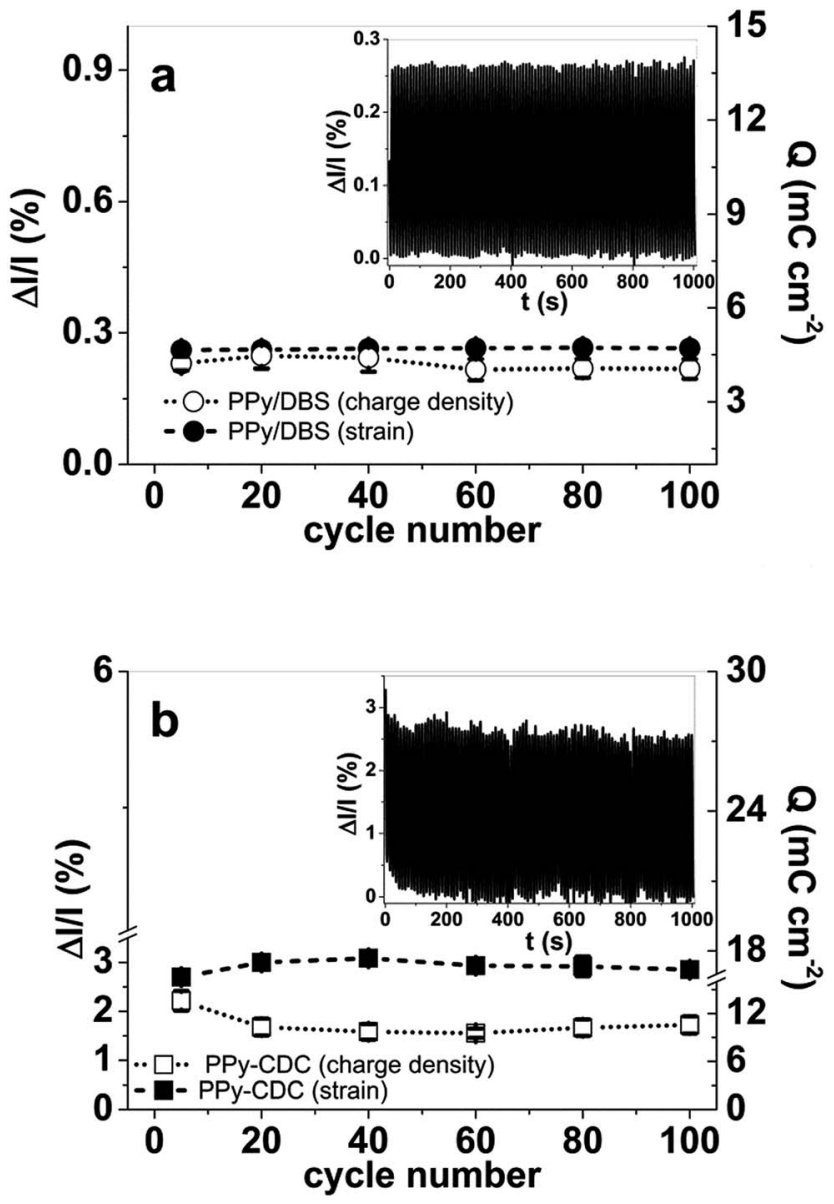

Fig. 6 Strain (filled circles) and charge density (empty circles) vs. cycle number (100 cycles) and time (inset) of (a) PPy/DBS and (b) PPy-CDC.

ratio decreased during actuation and polarization. Apparently some of the POM (with or without CDC) on the surface of the film was lost during actuation. POM anions contain also phosphorus, seen as two weak peaks at $2.014 \mathrm{keV}$ and $2.139 \mathrm{keV}$. In previous research ${ }^{18}$ it was discovered that POM is removed from the PPy film during redox cycles, which is detected by mass loss. While it is not likely that the large POM ions can be released from inside the films, some decrease in the $\mathrm{W}$ content is apparent.

The carbon peak $(0.26 \mathrm{keV})$ was relatively higher for the PPyCDC films, as expected. The EDX spectra for the samples not actuated (Fig. 7a and b) show a strong Na peak at $1.04 \mathrm{keV}$ that was absent from the spectra after actuation. The Na content was related to residues from the polymerization process. The fluoride peak at $0.68 \mathrm{keV}$ only appeared after actuation in the $\mathrm{TFSI}^{-}$ solution and is lower (as expected) for the reduced film. The presence of fluoride in the actuated PPy/DBS (Fig. 6a) and PPyCDC (Fig. 7b) samples revealed that either ion-exchange or additional doping of the PPy matrix had taken place; the latter is more likely as the content is significantly higher in the oxidized films and the original dopants were rather large to be mobile. Nevertheless, at least in the applied potential range the exchange of $\mathrm{TFSI}^{-}$did not influence markedly the actuation
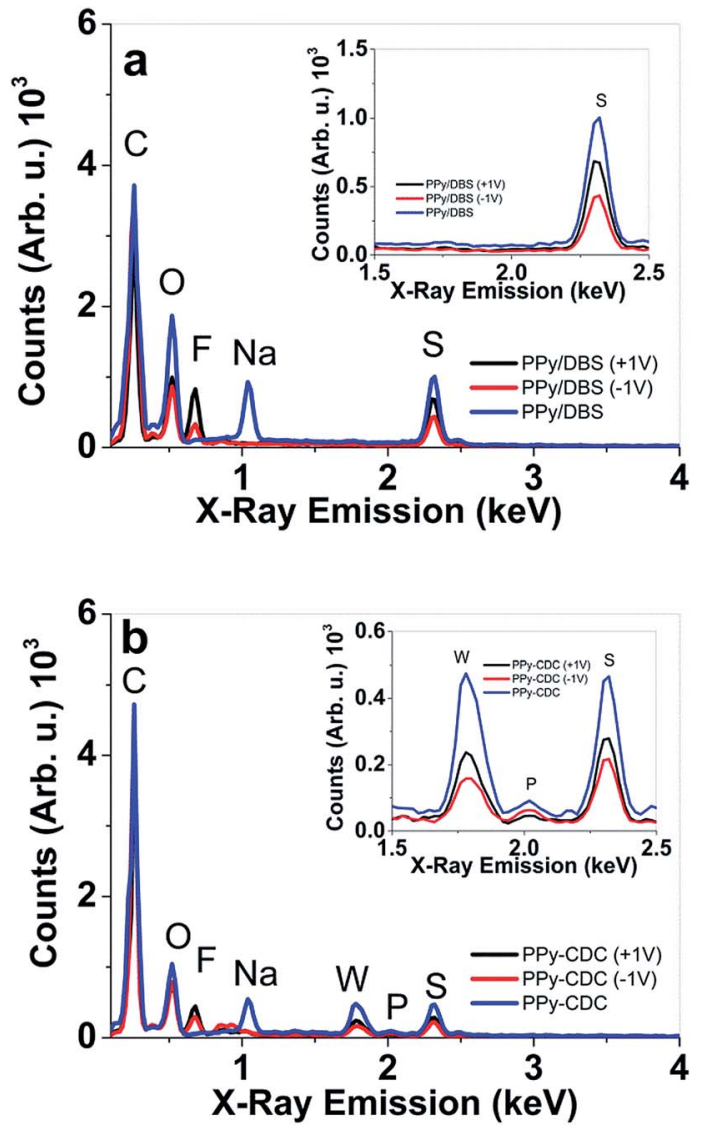

Fig. 7 EDX spectra of (a) PPy/DBS and (b) PPy-CDC samples (crosssection in the inset in the range 1.5-2.5 keV) before actuation (blue line) and after actuation oxidized (black line) at $+1 \mathrm{~V}(5 \mathrm{~min})$ in LiTFSI aqueous electrolyte and reduced (red line) at $-1 \mathrm{~V}(5 \mathrm{~min})$ in LiTFSI aqueous electrolyte.

properties in either the PPy/DBS or PPy-CDC films. It is also interesting that the incorporated fluoride content was relatively lower for the PPy-CDC films than for the PPy/DBS films. The ratio of sulfur $(2.32 \mathrm{keV})$ to carbon did not change too much but was found to be largest for the oxidized films, in agreement with the increased fluorine content.

\section{Conclusions}

We have demonstrated that the inclusion of CDC in PPy linear actuators (mediated by POM) can lead to highly improved strain (20 times higher) and stress (1.5 times higher) in comparison to that of PPy/DBS films. The main reason for such a high strain increase (up to $12 \%$ strain) relies on the drastic reduction of the elastic modulus of PPy-CDC films (7 MPa) in comparison to that of PPy/DBS films (70 MPa), which in part is attributed to the lower synthesis potential and reduced amount of cross-links and other chain defects. While the incorporation of CDC clearly increased capacitance, the actuation efficiency was actually improved: a 2.5 times increase in exchanged charge was accompanied by a 10-fold increase in strain. Meanwhile, a linear dependence of stress (strain) $v s$. charge was found for 
PPy/DBS actuators, and PPy-CDC exhibited quickly saturated stress/strain vs. charge curves. This phenomenon can be explained by the much faster response of PPy-CDC hybrids to potential steps, with the charge exchange occurring afterwards mostly dominated by the EDL charging process of the CDC material. The much faster response in turn is due to either the higher conductivity of PPy-CDC (especially in the reduced state) or the lower density; the latter is expressed by the SEM images revealing that CDC is bound within the PPy films turning the uniform PPy/DBS structure into a more modular form. Peaks of tungsten observed in the EDX spectra revealed that POM ions were embedded in the PPy film during polymerization and in most part stay in the PPy-CDC films also during actuation and polarization at relatively extreme potentials. Both PPy/DBS and PPy-CDC were found to undergo partial ion-exchange or additional doping in $\mathrm{TFSI}^{-}$solution, as evidenced by the appearance of fluoride peaks after actuation, which were more prominent in the oxidized form films. In conclusion, the free-standing films of PPy-CDC composites were demonstrated here as promising actuator materials.

\section{Acknowledgements}

The research was supported by European Union's Horizon 2020 research and innovation program under the Marie SklodowskaCurie grant agreement No. 641822 and partly by the European Union through the European Social Fund (MTT76) and Estonian Science Foundation, grant no. 9236.

\section{Notes and references}

1 A. D. Della Santa, A. De Rossi and A. Mazzoldi, Synth. Met., 1997, 90.2, 93-100.

2 L. Bay, K. West, P. Sommer-Larsen, S. Skaarup and M. Benslimane, Adv. Mater., 2003, 15, 310-313.

3 S. Hara, T. Zama, S. Sewa, W. Takashima and K. Kaneto, Chem. Lett., 2003, 32, 576-577.

4 S. Hara, T. Zama, W. Takashima and K. Kaneto, J. Mater. Chem., 2004, 14, 1516.

5 M.-A. De Paoli, et al., Electrochim. Acta, 1992, 37.7, 1173-1182.

6 R. Kiefer, N. Aydemir, J. Torop, P. a. Kilmartin, T. Tamm, F. Kaasik, A. Kesküla, J. Travas-Sejdic and A. Aabloo, SPIE, 2014, 9056, 90561V.
7 L. Valero, T. F. Otero and J. G. Martínez, ChemPhysChem, 2014, 15, 293-301.

8 E. Smela and N. Gadegaard, J. Phys. Chem. B, 2001, 105, 9395-9405.

9 J. Torop, A. Aabloo and E. W. H. Jager, Carbon, 2014, 80, 387395.

10 N. G. Sahoo, Y. C. Jung, H. H. So and J. W. Cho, Synth. Met., 2007, 157, 374-379.

11 J. C. Huang, Adv. Polym. Technol., 2002, 21, 299-313.

12 G. M. Suppes, B. a. Deore and M. S. Freund, Langmuir, 2008, 24, 1064-1069.

13 R. Kiefer, R. Temmer, T. Tamm, J. Travas-Sejdic, P. A. Kilmartin and A. Aabloo, Synth. Met., 2013, 171, 69-75.

14 J. G. Martinez, T. F. Otero and E. W. H. Jager, Langmuir, 2014, 30, 3894-3904.

15 M. Fuchiwaki and T. F. Otero, J. Mater. Chem. B, 2014, 2, 1954.

16 J. Torop, F. Kaasik, T. Sugino, A. Aabloo and K. Asaka, Electroact. Polym. Actuators Devices, 2010, vol. 7642, p. 76422A.

17 Y. Song, E. Wang, Z. Kang, Y. Lan and C. Tian, Mater. Res. Bull., 2007, 42, 1485-1491.

18 T. F. Otero, S. A. Cheng, E. Coronado, E. M. Ferrero and C. J. Gomez-Garcia, ChemPhysChem, 2002, 3, 808.

19 T. F. Otero, S. A. Cheng, D. Alonso and F. Huerta, J. Phys. Chem. B, 2000, 104, 10528-10533.

20 S. Herrmann, C. Ritchie and C. Streb, Dalton Trans., 2015, 44, 7092-7104.

21 P. S. Kishore, B. Viswanathan and T. K. Varadarajan, Nanoscale Res. Lett., 2008, 3, 14-20.

22 T. F. Otero and J. G. Martinez, Adv. Funct. Mater., 2014, 24, 1259-1264.

23 T. F. Otero, H. Grande and J. Rodriguez, J. Phys. Chem. B, 1997, 101, 8525-8533.

24 T. F. Otero, S. A. Cheng and F. Huerta, J. Phys. Chem. B, 2000, 104, 10522-10527.

25 N. Aydemir, T. Tamm, J. Travas-Sejdic, P. a. Kilmartin, A. Aabloo and R. Kiefer, SPIE, 2014, 9056, 905631.

26 R. Kiefer, J. G. Martinez, T. F. Otero, A. Kesküla, F. Kaasik, M. Harjo, R. Valner, V. Vaddepally, A.-L. Peikolainen and A. Aabloo, SPIE, 2015, 9430, 94301C. 